\title{
Increased Excitability of Afferent Neurons Innervating Rat Urinary Bladder after Chronic Bladder Inflammation
}

\author{
Naoki Yoshimura and William C. de Groat \\ Department of Pharmacology, University of Pittsburgh School of Medicine, Pittsburgh, Pennsylvania 15261
}

The properties of bladder afferent neurons in $L_{6}$ and $S_{1}$ dorsal root ganglia of adult rats were evaluated after chronic bladder inflammation induced by 2 week treatment with cyclophosphamide (CYP; $75 \mathrm{mg} / \mathrm{kg}$ ). Whole-cell patch-clamp recordings revealed that most $(70 \%)$ of the dissociated bladder afferent neurons from control rats were capsaicin sensitive, with highthreshold long-duration action potentials that were not blocked by tetrodotoxin (TTX; $1 \mu \mathrm{M}$ ). These neurons exhibited membrane potential relaxations during voltage responses elicited by depolarizing current pulses and phasic firing during sustained membrane depolarization. After CYP treatment, a similar proportion $(71 \%)$ of bladder afferent neurons were capsaicin sensitive with TTX-resistant spikes. However, the neurons were significantly larger in size (diameter $29.6 \pm 1.0 \mu \mathrm{m}$ vs $23.6 \pm 0.8$ $\mu \mathrm{m}$ in controls). TTX-resistant bladder afferent neurons from CYP-treated rats exhibited lower thresholds for spike activation $(-25.4 \pm 0.5 \mathrm{mV})$ than those from control rats $(-21.4 \pm 0.9 \mathrm{mV})$ and did not exhibit membrane potential relaxation during depolarization. Seventy percent of TTX-resistant bladder afferent neurons from CYP-treated rats exhibited tonic firing (average $12.3 \pm 1.4$ spikes during a 500 msec depolarizing pulse) versus phasic firing (1.2 \pm 0.2 spikes) in normal bladder afferent neurons. Application of 4-aminopyridine (1 mm) to normal TTXresistant bladder afferent neurons mimicked the changes in firing properties after CYP treatment. The peak density of an A-type $\mathrm{K}^{+}$current $\left(I_{\mathrm{A}}\right)$ during depolarizations to $0 \mathrm{mV}$ in TTXresistant bladder afferent neurons from CYP-treated rats was significantly smaller $(42.9 \mathrm{pA} / \mathrm{pF})$ than that from control rats (109.4 pA/pF), and the inactivation curve of the $I_{\mathrm{A}}$ current was displaced to more hyperpolarized levels by $\sim 15 \mathrm{mV}$ after CYP treatment. These data suggest that chronic inflammation induces somal hypertrophy and increases the excitability of C-fiber bladder afferent neurons by suppressing $I_{\mathrm{A}}$ channels. Similar electrical changes in sensory pathways may contribute to cystitis-induced pain and hyperactivity of the bladder.

Key words: dorsal root ganglion; tetrodotoxin; A-type $\mathrm{K}^{+}$ channels; urinary bladder; cyclophosphamide; inflammation; capsaicin
Chronic pathological conditions such as tissue inflammation or irritation can induce changes in the properties of somatic sensory pathways, leading to hyperalgesia and allodynia. Peripheral sensitization of primary afferents or changes in central synapses contribute to the increased pain sensation (for review, see McMahon, 1996; Millan, 1999). It has been documented that tissue inflammation in visceral organs such as the urinary bladder can also increase afferent nerve sensitivity to noxious and nonnoxious stimuli (Häbler et al., 1990; Sengupta and Gebhart, 1994). Changes in afferent excitability can elicit painful sensation as well as hyperactivity of the inflamed visceral organs. For example, patients receiving cyclophosphamide (CYP) for the treatment of neoplastic diseases often exhibit side effects of CYP therapy such as hemorrhagic cystitis, major symptoms of which are irritative voiding and gross hematuria (Stillwell and Benson, 1988). In addition, patients with interstitial cystitis, which is a painful chronic disorder of the urinary bladder of unknown etiology, exhibit urinary frequency, urgency, and severe suprapubic pain (Ho et al., 1997). Histological analysis of the bladder in these patients shows edema, vasodilation, and proliferation of nerve fibers with chronic infiltration of inflammatory cells such as mast cells (Johansson et al., 1997). Previous studies using animal

Received Jan. 4, 1999; revised March 10, 1999; accepted March 15, 1999.

This work was supported by National Institutes of Health (DK 49430 and DK 51420) and the American Paralysis Association (YA1-9801-2).

Correspondence should be addressed to Dr. Naoki Yoshimura, Department of Pharmacology, University of Pittsburgh School of Medicine, W1353 Biomedical Science Tower, Pittsburgh, PA 15261.

Copyright (C) 1999 Society for Neuroscience 0270-6474/99/194644-10\$05.00/0 models of chemically induced cystitis indicated that cystitis initiates bladder hyperactivity by sensitizing mechanosensitive afferents and/or recruitment of silent afferents that are normally unresponsive to mechanical stimuli such as bladder distension (Häbler et al., 1990; Sengupta and Gebhart, 1994; Dmitrieva and McMahon, 1996; Dmitrieva et al., 1997).

Recent studies (Gold et al., 1996a; Cardenas et al., 1997; Yoshimura and de Groat; 1997; Li et al., 1998) have used patchclamp methods and dissociated sensory neurons as model systems for evaluating indirectly the properties of afferent nerve terminals. It was discovered that proinflammatory agents such as prostaglandin $\mathrm{E}_{2}\left(\mathrm{PGE}_{2}\right)$, adenosine, and serotonin (5HT) modulate $\mathrm{Na}^{+}$and $\mathrm{K}^{+}$channel conductances in the cell bodies of sensory neurons, suggesting that tissue inflammation might alter ion channels in peripheral afferent terminals and thereby change the functional properties of afferent pathways (England et al., 1996; Gold et al., 1996b; Cardenas et al., 1997; Nicol et al., 1997). However, it has not been determined whether tissue inflammation can indeed alter the properties of ion channels in afferent neurons innervating inflamed tissue. Thus the present study investigated the electrical properties of bladder afferent neurons after chronic cystitis induced by CYP. CYP is metabolized in the liver to acrolein, an irritant substance that is excreted in the urine (Cox, 1979; Lantéri-Minet et al., 1995).

Bladder hyperreflexia in rats with CYP-induced cystitis is abolished by pretreatment with capsaicin, a neurotoxin specific for C-fiber afferents, indicating that bladder inflammation alters the activity of capsaicin-sensitive bladder afferent neurons 
(Maggi et al., 1992). In rat $\mathrm{L}_{6}-\mathrm{S}_{1}$ dorsal root ganglia (DRG), our recent study using immunohistochemical detection of neurofilament proteins and cobalt uptake for evaluating responses to capsaicin indicated that most $(60 \%)$ bladder afferent neurons are capsaicin sensitive and nearly all $(>95 \%)$ of these are $\mathrm{C}$-fiber neurons, which do not exhibit neurofilament immunoreactivity (Yoshimura et al., 1998). Previous studies also showed that capsaicin-sensitive bladder afferent neurons exhibit highthreshold $\mathrm{Na}^{+}$currents and action potentials that are resistant to tetrodotoxin (TTX) and usually express slowly inactivating A-type $\mathrm{K}^{+}$currents $\left(I_{\mathrm{A}}\right)$ that contribute to suppression of neuronal excitability (Yoshimura et al., 1996; Yoshimura, 1999). Blockade of $I_{\mathrm{A}}$ currents by 4-aminopyridine (4-AP) increased excitability (Yoshimura et al., 1996; Yoshimura, 1999). In this study, patch-clamp recording techniques were used to examine cystitis-induced changes in dissociated $\mathrm{C}$-fiber bladder afferent neurons that were identified by axonal tracing, sensitivity to capsaicin, and the presence of TTX-resistant action potentials. The results indicate that chronic bladder inflammation enhances the electrical excitability of $\mathrm{C}$-fiber bladder afferent neurons by suppressing slowly inactivating $I_{\mathrm{A}}$ channels.

Preliminary results of this study have been reported previously in abstract form (Yoshimura et al., 1997; Yoshimura and de Groat, 1998).

\section{MATERIALS AND METHODS}

Animal preparation. Experiments were performed on adult female Sprague Dawley rats (150-200 gm; purchased from Hilltop). Care and handling of animals were in accordance with institutional guidelines and approved by the University of Pittsburgh Institutional Animal Care and Use Committee. Chemical cystitis was induced by CYP, which is metabolized to acrolein. Acrolein is excreted in the urine and induces bladder inflammation (Cox, 1979; Lantéri-Minet et al., 1995). CYP (Sigma, St. Louis, MO) was injected intraperitoneally $(75 \mathrm{mg} / \mathrm{kg}$, every third day for 2 weeks) (Vizzard et al., 1996). Control animals received vehicle treatment (i.e., intraperitoneal injection of a corresponding volume of distilled water).

As described previously (Yoshimura et al., 1996, 1998; Yoshimura and de Groat, 1997), the population of DRG neurons that innervate the urinary bladder were labeled by retrograde axonal transport of a fluorescent dye, Fast Blue (4\% w/v) (Polyloy, Gross Umstadt, Germany) injected into the wall of the bladder in halothane-anesthetized animals $7 \mathrm{~d}$ before the dissociation. The dye was injected with a 28 gauge needle at three to six sites on the dorsal surface of the organ $(5-6 \mu$ per site, total volume of 20-30 $\mu$ l). Each injection site was washed with saline to minimize contamination of adjacent organs with the dye. Particular care was taken to avoid injections into the lumen, major blood vessels, or overlying fascial layers to minimize nonspecific labeling caused by dye leakage. No apparent leakage was observed.

Cell dissociation. Freshly dissociated neurons from DRG were prepared from halothane-anesthetized animals as described previously (Yoshimura et al., 1994, 1996). Briefly, $\mathrm{L}_{6}$ and $\mathrm{S}_{1} \mathrm{DRG}$ were dissected from control and CYP-treated animals and then dissociated in a shaking bath for $25 \mathrm{~min}$ at $35^{\circ} \mathrm{C}$ with $5 \mathrm{ml} \mathrm{DMEM} \mathrm{(Sigma)} \mathrm{containing} 0.3 \mathrm{mg} / \mathrm{ml}$ trypsin (Type 3, Sigma), $1 \mathrm{mg} / \mathrm{ml}$ collagenase (Type 1 , Sigma), and 0.1 $\mathrm{mg} / \mathrm{ml}$ deoxyribonuclease (Type 4, Sigma). Trypsin inhibitor (Type 2a, Sigma) was then added to neutralize the activity of trypsin. Individual DRG cell bodies were isolated by trituration and then plated on a poly-L-lysine-coated $35 \mathrm{~mm}$ Petri dishes.

Electrical recordings. Dye-labeled primary afferent neurons that innervate the urinary bladder were identified using an inverted phase-contrast microscope (Nikon, Tokyo, Japan) with fluorescent attachments (UV-1A filter; excitation wavelength, $365 \mathrm{~nm}$ ). Gigaohm-seal whole-cell recordings were performed within $6-8 \mathrm{hr}$ after cell dissociation at room temperature $\left(20-22^{\circ} \mathrm{C}\right)$ on each labeled neuron in a culture dish that usually contained three to seven labeled cells among a few hundred unlabeled neurons.

The internal solution contained (in mM): $\mathrm{KCl} 140, \mathrm{CaCl}_{2} 1, \mathrm{MgCl}_{2} 2$, EGTA 11, HEPES 10, Mg-ATP 2, and Tris-GTP 0.4 adjusted to $\mathrm{pH} 7.4$ with $\mathrm{KOH}$. Patch electrodes had resistances of $1-4 \mathrm{M} \Omega$ when filled with the internal solution. Neurons were superfused at a flow rate of 1.5 $\mathrm{ml} / \mathrm{min}$ with an external solution containing (in $\mathrm{mM}$ ): $\mathrm{NaCl} 150, \mathrm{KCl} 5$, $\mathrm{CaCl}_{2} 2.5, \mathrm{MgCl}_{2}$ 1, HEPES 10, and D-glucose 10, adjusted to $\mathrm{pH} 7.4$ with $\mathrm{NaOH}$. All recordings were made with an Axopatch-1D patchclamp amplifier (Axon Instruments, Foster City, CA), and data were acquired and analyzed by PCLAMP software (Axon Instruments). Cell membrane capacitances were obtained by reading the value for wholecell input capacitance neutralization directly from the amplifier. Durations of action potentials were measured at $50 \%$ of the spike amplitude. In current-clamp recordings, data are presented from neurons that exhibited resting membrane potentials greater than $-40 \mathrm{mV}$ and action potentials that overshot $0 \mathrm{mV}$. In a protocol examining firing characteristics, action potentials were elicited by depolarizing current pulses (duration $500 \mathrm{msec}$ ), the intensity of which was set to a value that was just suprathreshold for inducing a single action potential during a $5 \mathrm{msec}$ depolarizing stimulus pulse. The number of spikes was averaged during five stimulation pulses. TTX was applied to neurons by injection into the external solution. Capsaicin $(1 \mu \mathrm{M})$ was applied directly onto the cell by pressure ejection (Picospritzer, General Valve, Fairfield, NJ) through a glass pipette (10-20 $\mu \mathrm{m}$ tip diameter, $500 \mathrm{msec}$ at 5-10 psi). Inward shift of holding currents in voltage-clamp recordings was observed in capsaicin-sensitive cells. Capsaicin was dissolved in the normal external solution containing $10 \%$ alcohol and $10 \%$ Tween 80 at a concentration of $5 \mathrm{~mm}$ and then diluted in the external solution before experiments. No effects were detected by application of alcohol and Tween 80 in concentrations as high as $0.2 \%$.

In voltage-clamp recordings, the filter was set to $-3 \mathrm{~dB}$ at $2000 \mathrm{~Hz}$. Leak currents were subtracted by $\mathrm{P} / 4$ pulse protocol, and the series resistance was compensated by $50-60 \%$. The voltage error did not exceed $5 \mathrm{mV}$ after compensation of the series resistance, and a charging time constant of the voltage clamp was $<300 \mu \mathrm{sec}$, which was faster than gating properties of outward $\mathrm{K}^{+}$currents in this study. For the isolation of $\mathrm{K}^{+}$currents, the external solution was changed to one containing (in $\mathrm{mm}$ ): choline-Cl 150, $\mathrm{KOH} 5, \mathrm{CaCl}_{2} 0.03$, HEPES $10, \mathrm{Mg}(\mathrm{OH})_{2} 3$, and D-glucose 10, adjusted to $\mathrm{pH} 7.4$ with $\mathrm{HCl}$.

Analysis. All data are expressed as means \pm SEM. Steady-state activation and inactivation data were fitted by the modified Boltzmann equation $G / G_{\max }=1 /\left[1+\exp \left(V_{\mathrm{h}}-V_{\mathrm{m}}\right) / k\right]$, where $G$ is the conductance, $G_{\max }$ is the fitted maximal conductance, $V_{\mathrm{h}}$ is the membrane potential for half-activation and inactivation, $V_{\mathrm{m}}$ is the command potential, and $k$ is the slope factor. The conductance $G$ was determined from the relation: $G=I /\left(V_{\mathrm{m}}-E_{\mathrm{k}}\right)$, where $I$ is the measured membrane current, $V_{\mathrm{m}}$ is the voltage step, and $E_{\mathrm{k}}$ is the equilibrium potassium potential that was calculated to be $-84 \mathrm{mV}$ (external $\left[\mathrm{K}^{+}\right]$was $5 \mathrm{~mm}$ and internal $\left[\mathrm{K}^{+}\right]$was $140 \mathrm{~mm}$ ). Statistical differences between data from control and CYPtreated animals were determined by Mann-Whitney $U$ test. A level of $p<0.05$ was considered to be statistically significant.

\section{RESULTS}

\section{CYP-induced cystitis}

After chronic CYP treatment, bladder weight $(168.2 \pm 6.8 \mathrm{mg}$, $n=11)$ was significantly $(p<0.01)$ greater than that of control rats $(84.6 \pm 5.2 \mathrm{mg}, n=10)$. Gross visual inspection of the bladder in CYP-treated animals revealed mucosal erosion, edema, and occasional petechial hemorrhage.

\section{Action potential and passive membrane characteristics Control animals}

As noted in previous experiments (Yoshimura et al., 1996; Yoshimura and de Groat., 1997; Yoshimura, 1999), bladder afferent neurons could be divided into two populations according to the sensitivity of their action potentials to TTX $(1 \mu \mathrm{M})$ in currentclamp recordings. In control animals, $\sim 70 \%$ of bladder afferent neurons (30 of 41 neurons) exhibited long-duration $(7.9 \pm 0.5$ msec) action potentials that were resistant to TTX in a concentration up to $6 \mu \mathrm{M}$ (Fig. 1), whereas the remaining 11 bladder afferent neurons exhibited action potentials that were reversibly blocked by $1 \mu \mathrm{M}$ TTX (Yoshimura et al., 1996). The action potentials were activated by depolarizing current pulses at the mean threshold of $-21.4 \pm 0.9 \mathrm{mV}$. This type of cell was small in 

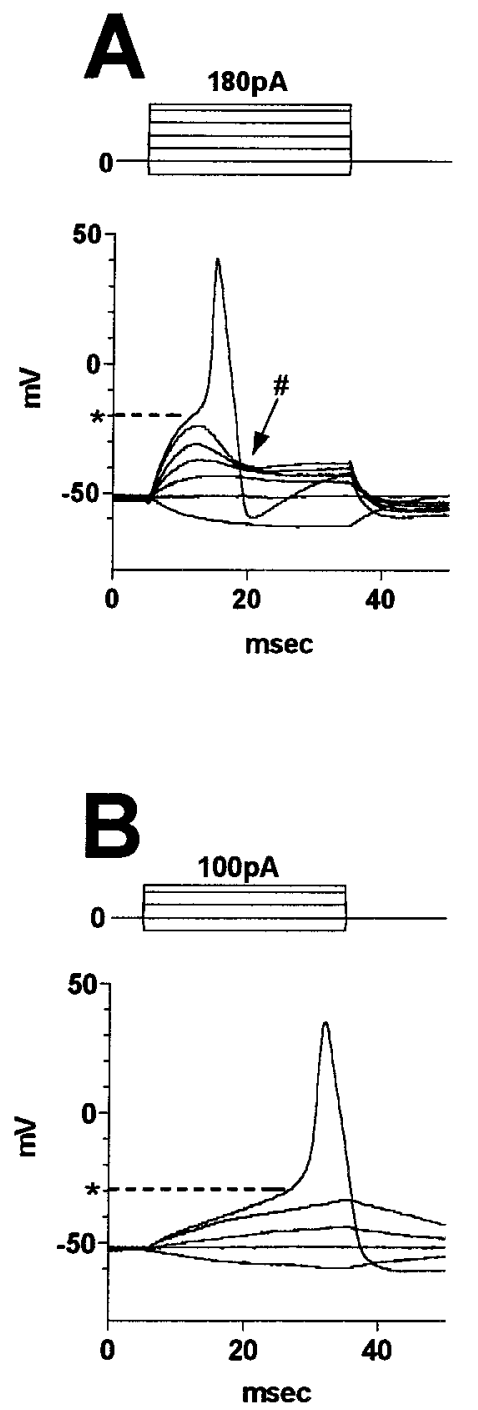
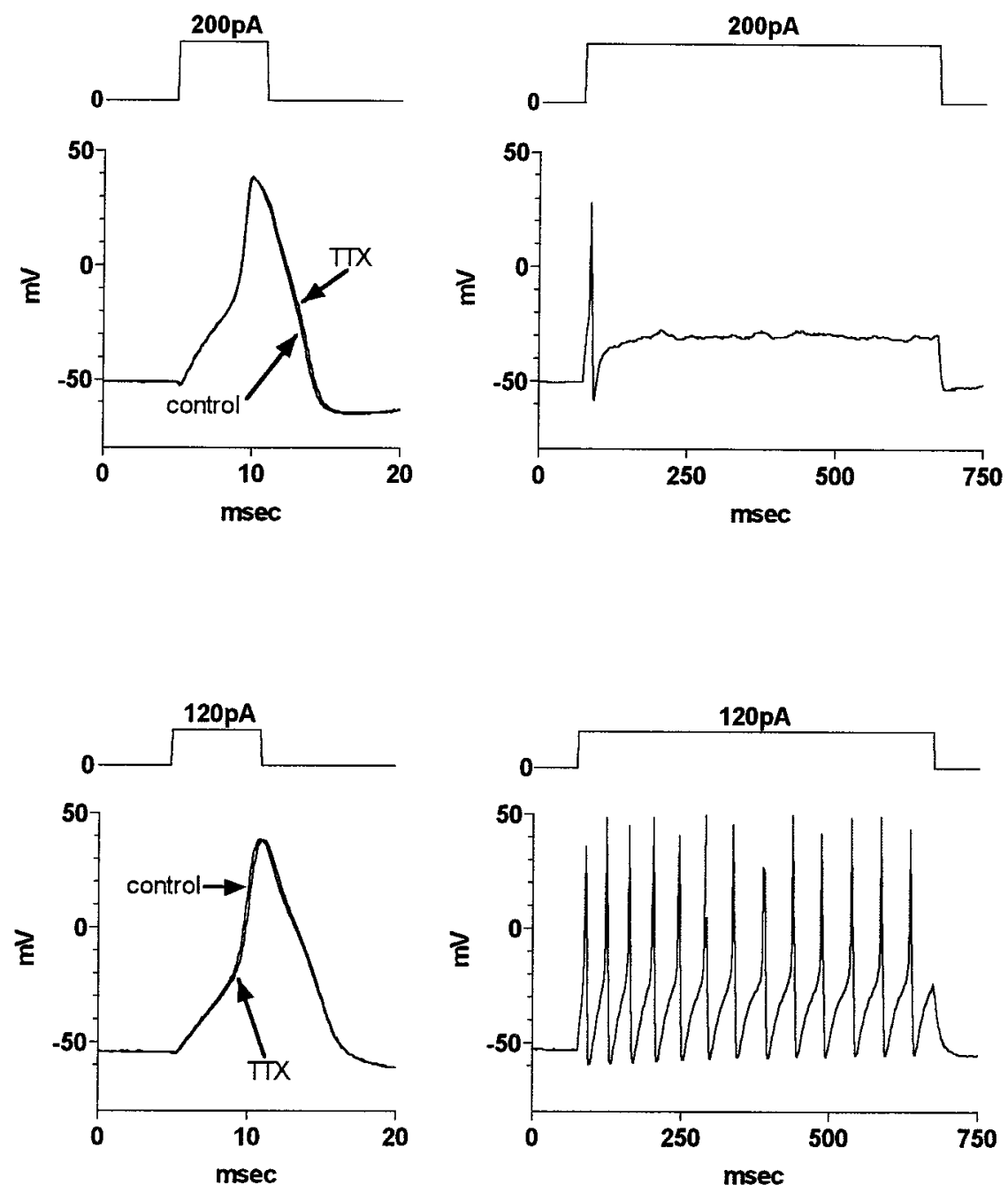

Figure 1. Characteristics of action potentials in capsaicin-sensitive bladder afferent neurons with TTX-resistant action potentials from control $(A)$ and CYP-treated cystitis rats $(B)$. The left panels are voltage responses and action potentials evoked by 30 msec depolarizing current pulses injected through the patch pipette in current-clamp conditions. Asterisks with dashed lines indicate the thresholds for spike activation $(-20 \mathrm{mV}$ in $A$ and $-29 \mathrm{mV}$ in $B)$. In $A$, \# indicates that the neuron ( $24 \mu \mathrm{m}$ in diameter) from the control rat exhibited membrane potential relaxation during depolarizing current injections, which was not detected in the neuron $(31 \mu \mathrm{m}$ in diameter) from the CYP-treated rat $(B)$. The middle panels show the effects of TTX application $(1 \mu \mathrm{M})$ on action potentials. The right panels show firing patterns during membrane depolarization (500 msec of duration). The current intensity was set to the threshold value for inducing single spikes with $5 \mathrm{msec}$ current pulses as indicated in middle panels. The pulse protocols are shown in the insets.

size, with mean diameters and cell input capacitance of $23.6 \pm 0.8$ $\mu \mathrm{m}$ and $28.2 \pm 1.8 \mathrm{pF}$, respectively. In 30 bladder afferent neurons with TTX-resistant spikes, capsaicin application $(1 \mu \mathrm{M})$ produced inward currents (average peak amplitude of $2.21 \pm 0.20$ $\mathrm{nA}$; range, $0.4-2.8 \mathrm{nA}$ ) at the holding potential of $-60 \mathrm{mV}$ in 28 neurons $(93 \%)$, whereas the remaining two neurons were not sensitive to capsaicin. In bladder afferent neurons with TTXresistant spikes, depolarizing current pulses to -45 to $-40 \mathrm{mV}$ from the resting membrane potentials $(-50$ to $-55 \mathrm{mV})$ elicited voltage responses with a prominent relaxation that was evident at intensities below the threshold for evoking a spike (Fig. 1A). This relaxation was not observed in neurons with TTX-sensitive spikes (Yoshimura et al., 1996). The firing pattern during a sustained membrane depolarization was also different in TTX-resistant and TTX-sensitive bladder neurons. TTX-resistant bladder afferent neurons from control rats exhibited a phasic pattern of firing
(1.2 \pm 0.2 spikes, $n=30)$ during membrane depolarization (500 msec of duration) when the current intensity was set to the value just above the threshold for inducing spike activation with 5 msec pulses (Fig. 1, Table 1), whereas TTX-sensitive bladder neurons showed repetitive firings $(14.4 \pm 1.3 \mathrm{spikes} / 500 \mathrm{msec}$ pulse, $n=11$ ).

\section{CYP-treated animals}

A similar proportion (34 of 46 neurons, 74\%) of bladder afferent neurons from CYP-treated rats exhibited long-duration (6.6 \pm $0.5 \mathrm{msec}$ ) TTX-resistant action potentials (Fig. 1). In addition, nearly all (94\%) of the TTX-resistant bladder afferent neurons from CYP-treated rats were sensitive to capsaicin $(1 \mu \mathrm{M})$, as observed in control animals. In addition, the average peak amplitude of capsaicin-induced currents $(2.35 \pm 0.17 \mathrm{nA}$; range, $0.9-$ $3.6 \mathrm{nA}$ ) in TTX-resistant bladder afferent neurons from CYP- 


\begin{tabular}{|c|c|c|}
\hline & Control & CYP-treated \\
\hline No. of cells & $n=30$ & $n=34$ \\
\hline Diameter $(\mu \mathrm{m})$ & $23.6 \pm 0.8$ & $29.6 \pm 1.0^{* *}$ \\
\hline Input capacitance $(\mathrm{pF})$ & $28.2 \pm 1.8$ & $41.8 \pm 3.1^{* *}$ \\
\hline RMP (mV) & $-53.5 \pm 2.0$ & $-51.5 \pm 1.7$ \\
\hline Spike threshold $(\mathrm{mV})$ & $-21.4 \pm 0.9$ & $-25.4 \pm 0.5^{*}$ \\
\hline Spike duration (msec) & $7.9 \pm 0.5$ & $6.6 \pm 0.5$ \\
\hline $\begin{array}{l}\text { No. of action potentials ( } 500 \mathrm{msec} \text { depo } \\
\text { larization) }\end{array}$ & $1.2 \pm 0.2$ & $12.3 \pm 1.4^{* *}$ \\
\hline No. of cells & $n=25$ & $n=22$ \\
\hline$I_{\mathrm{A}}$ current density $(\mathrm{pA} / \mathrm{pF})($ at $0 \mathrm{mV})$ & $109.4 \pm 9.4$ & $42.9 \pm 6.6^{* *}$ \\
\hline $\begin{array}{l}\text { Decay time constant }(\tau) \text { of } I_{\mathrm{A}} \text { current } \\
\quad(\mathrm{msec})\end{array}$ & $189.6 \pm 8.8$ & $201.2 \pm 7.6$ \\
\hline$I_{\mathrm{KV}}$ current density $(\mathrm{pA} / \mathrm{pF})($ at $0 \mathrm{mV})$ & $52.8 \pm 7.1$ & $60.2 \pm 6.1$ \\
\hline
\end{tabular}

$\overline{\text { Values are mean } \pm \text { SEM. }{ }^{*} \mathrm{p}<0.05 \text { and } * * \mathrm{p}<0.01 \text { indicate differences compared }}$ with control animals. RMP, Resting membrane potentials. Number of action potentials was obtained by injections of depolarizing current pulses (500 msec duration).

treated rats did not differ from that in the neurons from control rats. However these TTX-resistant bladder afferent neurons from CYP-treated rats did not exhibit the membrane potential relaxation during depolarizing current injection. In addition, the mean threshold for spike activation in TTX-resistant bladder afferent neurons from CYP-treated rats was significant lower $(-25.4 \pm$ $0.5 \mathrm{mV}$ ) than in TTX-resistant bladder neurons from control animals. Sustained membrane depolarizations (500 msec duration) produced trains of action potentials (i.e., a tonic pattern of firing) in 25 of 34 bladder neurons (74\%) with TTX-resistant spikes from CYP-treated rats. The average number of action potentials in all 34 TTX-resistant neurons from CYP-treated rats was significantly $(p<0.01)$ greater $(12.3 \pm 1.4$ spikes during 500 msec of stimulation) than in control animals (Table 1). In addition, the mean diameter $(29.6 \pm 1.0 \mu \mathrm{m})$ and cell input capacitance $(41.8 \pm 3.1 \mathrm{pF})$ of TTX-resistant bladder neurons in CYPtreated rats were significantly greater than in control rats, indicating somal hypertrophy of these neurons after CYPinduced bladder inflammation (Table 1).

\section{Effects of $4-A P$}

Because our previous studies (Yoshimura et al., 1996; Yoshimura, 1999) demonstrated that membrane potential relaxation during depolarizing current injection in TTX-resistant bladder neurons is caused by activation of low-threshold slowly decaying $I_{\mathrm{A}}$ currents, 4-AP, an $\mathrm{I}_{\mathrm{A}}$ channel blocker, was tested on neuronal properties in control animals. After application of 4-AP (1 mM), membrane potential relaxation during depolarizing current injections disappeared in bladder afferent neurons with TTX-resistant spikes (Fig. 2). Along with the 4-AP-induced suppression of membrane potential relaxation, the average threshold for spike activation in these neurons was significantly lowered by $\sim 5 \mathrm{mV}$ to $-26.8 \pm 1.8 \mathrm{mV}(n=6)$ (Fig. 2 , Table 1$)$. In addition, after 4-AP application, the firing during sustained membrane depolarization in these TTX-resistant bladder afferent neurons changed from a phasic to a tonic pattern (Fig. 2). The averaged number of action potentials during $500 \mathrm{msec}$ of stimulation after 4-AP application was significantly $(p<0.01)$ greater $(14.1 \pm 2.0$ spikes $)$ than the control value, but not different from the value obtained in CYPtreated rats.

\section{$I_{\text {A }}$ current characteristics}

After action potential properties and capsaicin sensitivity were examined, the characteristics of $I_{\mathrm{A}}$ currents were evaluated in voltage-clamp recordings by switching to an external solution that suppressed $\mathrm{Na}^{+}$and $\mathrm{Ca}^{2+}$ currents. This solution replaced $\mathrm{Na}^{+}$ ions with an equimolar substitution of choline chloride and reduced $\mathrm{Ca}^{2+}$ ions to $0.03 \mathrm{~mm}$ (Elliott and Elliott, 1993). The outward currents recorded under these conditions appeared to be carried by $\mathrm{K}^{+}$ions because the outward currents were totally blocked by the inclusion of 4-AP (5 mM) and TEA $(50 \mathrm{~mm})$ in the external solutions, and the reversal potential of the instantaneous tail currents under these conditions was close $(-78 \mathrm{mV})$ to the theoretical reversal potential for $\mathrm{K}^{+}$ions calculated by Nernst equation (data not shown).

Because $I_{\mathrm{A}}$ is activated by depolarizing voltage steps from hyperpolarized membrane potentials and inactivated when the membrane potential is maintained at a depolarized level more than $-40 \mathrm{mV}$ (Belluzzi et al., 1985, Rudy, 1988; Yoshimura et al., 1996), an estimate of the $I_{\mathrm{A}}$ current was obtained by the difference in the currents activated by depolarizing voltage pulses (to $0 \mathrm{mV}$ ) from a holding potential of $-40 \mathrm{mV}$ and from hyperpolarized holding potentials (i.e., as low as $-130 \mathrm{mV}$ ). Figure $3 A, D$ shows the superimposed outward $\mathrm{K}^{+}$currents induced by depolarization to $0 \mathrm{mV}$ from different holding potentials $(-40,-60$, and $-100 \mathrm{mV}$ ) in bladder afferent neurons with TTX-resistant spikes from control and CYP-treated rats, respectively. In TTXresistant bladder neurons from control rats, the total outward current elicited at $0 \mathrm{mV}$ from a holding potential of $-60 \mathrm{mV}$ was larger than the current activated from a holding potential of -40 $\mathrm{mV}$ (Fig. 3A), whereas in TTX-resistant neurons from CYPtreated rats no difference in outward currents was observed by depolarizations to $0 \mathrm{mV}$ from holding potentials of -40 and -60 $\mathrm{mV}$ (Fig. 3D). On the other hand, an increase in outward currents in response to depolarizing pulses (to $0 \mathrm{mV}$ ) was observed in TTX-resistant neurons from both groups of animals when the holding potential was shifted to $-100 \mathrm{mV}$ (Fig. $3 A, D$ ).

Figure $3 B, E$ shows the time dependence of $I_{\mathrm{A}}$ currents in TTX-resistant bladder afferent neurons from control and CYPtreated animals, respectively. The $I_{\mathrm{A}}$ currents were obtained by the subtraction method for currents activated by depolarization to $0 \mathrm{mV}$ from holding potentials of -40 and $-120 \mathrm{mV}$. In these neurons, $I_{\mathrm{A}}$ currents were slowly inactivated during a $300 \mathrm{msec}$ depolarization, and the decay phase of the currents was well fitted by single exponential curves with time constants $(\tau)$ of $176.6 \mathrm{msec}$ in the control rat (Fig. 3B) and $169.5 \mathrm{msec}$ in the CYP-treated rat (Fig. $3 E$ ). Using the same pulse protocols, the averaged time constants of the decay phase of $I_{\mathrm{A}}$ currents were not different between control (189.6 $\pm 8.8 \mathrm{msec}, n=25)$ and CYP-treated animals $(201.2 \pm 7.6 \mathrm{msec}, n=22)$ (Table 1$)$. However, the peak current density of $I_{\mathrm{A}}$ currents evoked by depolarization to $0 \mathrm{mV}$ (also calculated by the subtraction method) was significantly ( $p<$ 0.01) smaller in CYP-treated rats $(42.9 \pm 6.6 \mathrm{pA} / \mathrm{pF})$ than in control rats $(109.4 \pm 9.4 \mathrm{pA} / \mathrm{pF})$ (Table 1$)$. On the other hand, the plateau current density of sustained $\mathrm{K}^{+}$currents (i.e., delayed rectifier, $I_{\mathrm{KV}}$ ) elicited in TTX-resistant bladder neurons by depolarization to $0 \mathrm{mV}$ from a holding potential of $-40 \mathrm{mV}$ was not different between control and CYP-treated animals $(52.8 \pm 7.1$ $\mathrm{pA} / \mathrm{pF}$ and $60.2 \pm 6.1 \mathrm{pA} / \mathrm{pF}$, respectively) (Fig. $3 A, D$, Table 1). Figure $3 C, F$ shows the effect of 4 -AP $(2 \mathrm{~mm})$ on $I_{\mathrm{A}}$ currents in TTX-resistant bladder afferent neurons from both groups of animals. The reduction in outward $\mathrm{K}^{+}$currents activated from a 

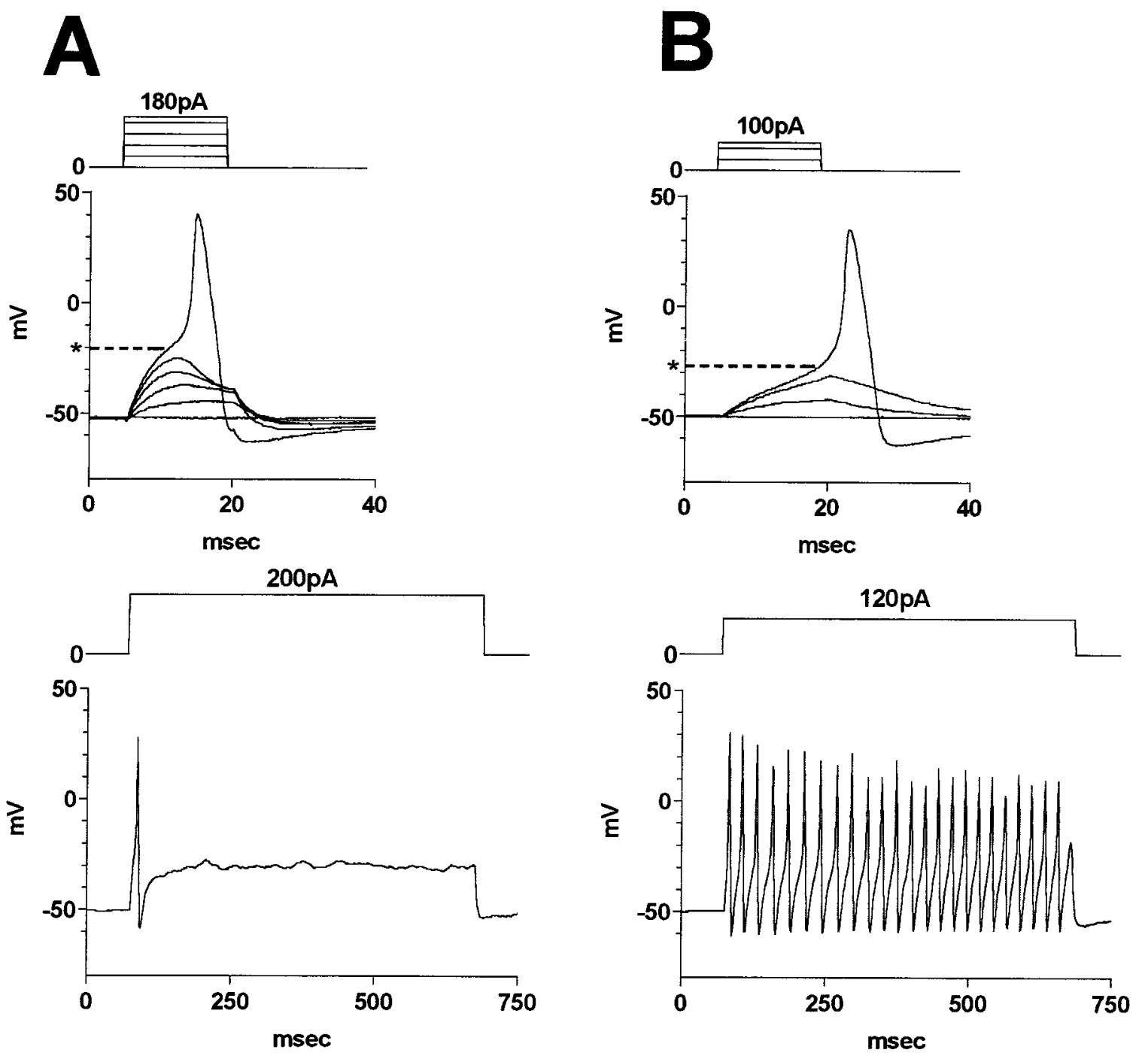

Figure 2. Effects of 4-AP, an $I_{\mathrm{A}}$ channel blocker, on voltage responses, TTX-resistant action potentials, and firing characteristics of a bladder afferent neuron from a control rat. $A$, Predrug control. $B$, After 4-AP application $(1 \mathrm{~mm})$. The top panels are voltage responses and action potentials evoked by $15 \mathrm{msec}$ depolarizing current pulses injected through the patch pipette in current-clamp conditions. The bottom panels are firing characteristics of action potentials during membrane depolarization $(500 \mathrm{msec}$ of duration). Note that action potentials in this neuron were evoked at thresholds (dashed lines) of -20 and $-27 \mathrm{mV}$ in the absence and presence of 4-AP, respectively, and that trains of action potentials (i.e., tonic pattern of firing) occurred after 4-AP application $(B$, bottom tracing), but only a single action potential was evoked before 4-AP application $(A$, bottom tracing).

holding potential of $-120 \mathrm{mV}$ after application of 4-AP was equal in amplitude and similar in time course to the estimated $I_{\mathrm{A}}$ currents obtained by subtraction of the currents activated from holding potentials of -40 and $-120 \mathrm{mV}$. This indicates that 4-AP suppressed $I_{\mathrm{A}}$ currents in TTX-resistant bladder afferent neurons from control and CYP-treated rats.

Although the $I_{\mathrm{A}}$ currents in TTX-resistant bladder neurons from both groups of rats had a similar time dependence and were sensitive to 4-AP, the $I_{\mathrm{A}}$ current in control animals could be elicited by depolarizing voltage steps from a holding potential $(-60 \mathrm{mV})$ equivalent to the physiological resting membrane potential, whereas an $I_{\mathrm{A}}$ current could not be detected in CYPtreated animals under the same conditions (Fig. 3A,D), suggesting that there was a different in the voltage dependence of inactivation in the $I_{\mathrm{A}}$ currents in the two groups of bladder neurons. Therefore, in the next set of experiments, the inactivation characteristics of the $I_{\mathrm{A}}$ current were examined by a pulse protocol, in which the $\mathrm{K}^{+}$current was activated by a depolarizing voltage step to $0 \mathrm{mV}$ after $500 \mathrm{msec}$ conditioning prepulses ranging from -130 to $-30 \mathrm{mV}$ with $10 \mathrm{mV}$ increments. The inactivation curve was plotted as the normalized peak conductance of $I_{\mathrm{A}}$ currents $(G /$ $\left.G_{\max }\right)$ versus the potentials of the conditioning prepulses $\left(V_{\mathrm{m}}\right)$ in nine bladder afferent neurons from control animals in which action potentials were not affected by TTX in the normal external solution. The $I_{\mathrm{A}}$ current in TTX-resistant neurons in control animals started to inactivate at membrane potentials positive to $-110 \mathrm{mV}$ and were nearly totally inactivated by depolarizing prepulses to $-40 \mathrm{mV}$. The data were well fitted by the modified Boltzmann equation with the half-maximal conductance $\left(V_{\mathrm{h}}\right)$ of $-74.2 \mathrm{mV}$ and a slope factor $(k)$ of $-9.6 \mathrm{mV}$. This inactivation curve indicates that $10-20 \%$ of the maximum current could be elicited at membrane potentials in the range of -60 to $-50 \mathrm{mV}$, which is equivalent to the resting membrane potential level (Fig. $4 A$ ). In contrast, the $I_{\mathrm{A}}$ currents in TTX-resistant bladder neurons from CYP-treated rats were inactivated at more negative membrane potentials. The current was almost negligible when the 

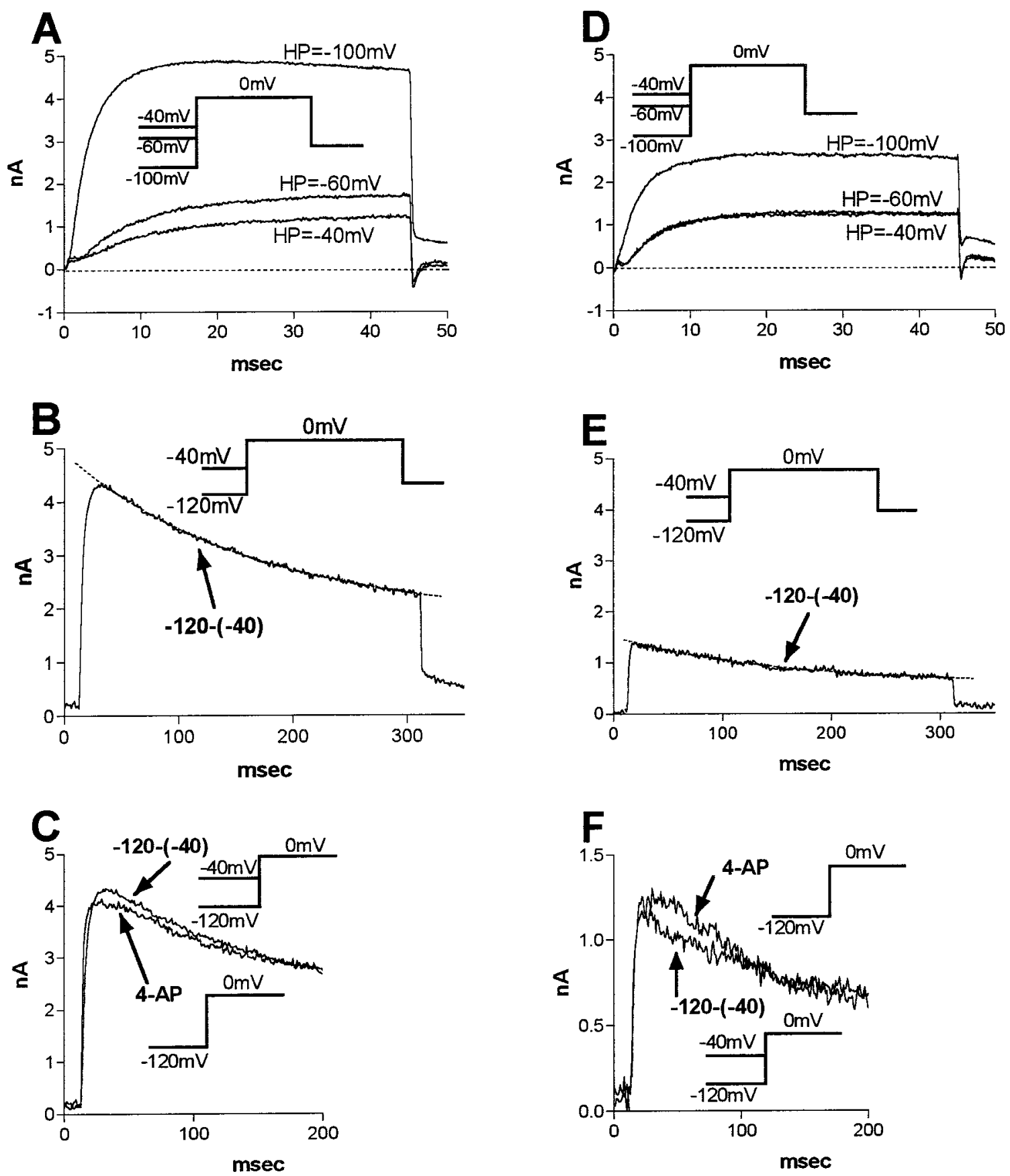

Figure 3. Characteristics of $I_{\mathrm{A}}$ current in bladder afferent neurons with TTX-resistant action potentials. Inward currents were suppressed by equimolar substitution of choline for $\mathrm{Na}^{+}$ions and reduction of $\mathrm{Ca}^{2+}$ ions in the external solution. $A-C$, One neuron from a control rat. $D-F$, One neuron from a CYP-treated rat. $A$ and $D$ show superimposed outward $\mathrm{K}^{+}$currents evoked by voltage steps to $0 \mathrm{mV}$ from holding potentials of $-100,-60$, and -40 $\mathrm{mV}$ in the neurons from control $(A)$ and CYP-treated rats $(D) . B$ and $E$ show time dependence of the decay phase of $I_{\mathrm{A}}$ currents in the neurons from control $(B)$ and CYP-treated rats $(E) . I_{\mathrm{A}}$ currents were obtained by subtraction of the $\mathrm{K}^{+}$currents evoked by depolarization to $0 \mathrm{mV}$ from holding potentials of -40 and $-120 \mathrm{mV}[-120-(-40)]$. $C$ and $F$ show the effects of 4-AP $(2 \mathrm{mM})$ on $I_{\mathrm{A}}$ currents in TTX-resistant bladder afferent neurons from control $(C)$ and CYP-treated rats $(F)$. The $I_{\mathrm{A}}$ currents were obtained by the subtraction method described above. Two traces are shown in each record: (1) tracing obtained by subtraction of the currents evoked from two holding potentials [-120-(-40)], and (2) tracing obtained by subtraction of total outward $\mathrm{K}^{+}$currents evoked from $-120 \mathrm{mV}$ holding potential before and after 4-AP application (4-AP). Note that the two current traces in each record are similar, indicating that 4-AP suppresses $I_{\mathrm{A}}$ currents in both control and CYP-treated rats. The pulse protocols are shown in the insets.

holding membrane potential was in the range of -60 to $-50 \mathrm{mV}$. The inactivation curve for CYP-treated animals was displaced to more hyperpolarized levels by $\sim 15 \mathrm{mV}$ in comparison with control animals. $V_{\mathrm{h}}$ and $k$ for inactivation of the $I_{\mathrm{A}}$ currents in TTX-resistant bladder neurons from CYP-treated rats were -90.2 and $-11.9 \mathrm{mV}$, respectively $(n=10)$ (Fig. $4 A$ ).
In contrast to the difference in inactivation characteristics, the voltage dependence of activation of the $I_{\mathrm{A}}$ current in TTXresistant bladder afferent neurons did not differ between control and CYP-treated rats. Activation of the $I_{\mathrm{A}}$ currents was investigated by measuring the differences of the peak conductance $(G)$ of outward $\mathrm{K}^{+}$currents evoked by voltage steps from -80 to +30 
Figure 4. Steady-state activation and inactivation characteristics of $I_{\mathrm{A}}$ current in bladder afferent neurons with TTX-resistant spikes from control and CYP-treated rats. $A$, Inactivation characteristics of $I_{\mathrm{A}}$ current in control animals $(n=9)(\mathbf{\Lambda})$ and CYP-treated animals $(n=10)$ $(\triangle)$. Relative peak conductance of $I_{\mathrm{A}}$ currents normalized to the maximal conductance of $I_{\mathrm{A}}$ currents $\left(G / G_{\max }\right)$ were plotted against membrane potentials. $V_{\mathrm{h}}$ and $k$ were obtained by fitting curves using the modified Boltzmann equation. $B$, Activation characteristics of $I_{\mathrm{A}}$ current obtained in the neurons from control animals $(n=9)(\boldsymbol{\square})$ and CYP-treated animals $(n=$ 10) ( $\square$ ). Relative $I_{\mathrm{A}}$ conductances normalized to the maximal $I_{\mathrm{A}}$ conductance $\left(G / G_{\max }\right)$ were plotted against membrane potentials. Note that $V_{\mathrm{h}}$ for $I_{\mathrm{A}}$ inactivation in the neurons from CYPtreated rats $(-90.2 \mathrm{mV})$ was displaced to more hyperpolarized levels than those from control rats $(-74.2 \mathrm{mV})$.
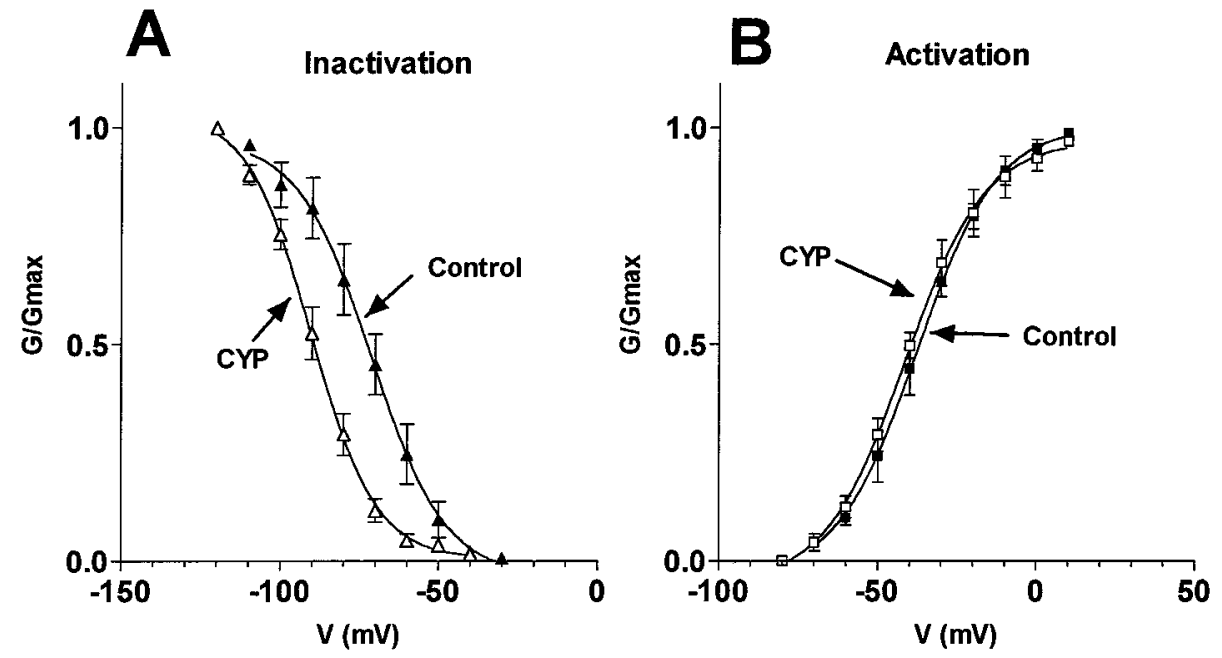

$\mathrm{mV}$ from two different holding potentials of -40 and $-120 \mathrm{mV}$. $G$ was then normalized with respect to the calculated maximal conductance $G_{\text {max }}$. In this manner, the $I_{\mathrm{A}}$ current in bladder afferent neurons with TTX-resistant spikes from control rats was elicited by depolarizations positive to $-60 \mathrm{mV}$, with $V_{\mathrm{h}}$ occurring at the membrane potential of $-40.8 \mathrm{mV}$ and with a slope factor of $9.5 \mathrm{mV}$ according to the modified Boltzmann equation $(n=9)$. Similarly, $V_{\mathrm{h}}$ and $k$ of the $I_{\mathrm{A}}$ current activation of TTX-resistant neurons from CYP-treated animals were -37.1 and $11.3 \mathrm{mV}$, respectively $(n=10)$ (Fig. $4 B)$.

\section{DISCUSSION}

The present results indicate that CYP-induced chronic inflammation of the lower urinary tract in the adult rat can induce somal hypertrophy and increase the electrical excitability of $\mathrm{C}$-fiber afferent neurons innervating the inflamed bladder. In control animals, bladder afferent neurons exhibiting TTX-resistant spikes had higher thresholds for initiating an action potential attributable to the presence of slow-inactivating $I_{\mathrm{A}}$ current. However, after CYP-induced chronic cystitis, bladder afferent neurons with TTX-resistant spikes exhibited a lower threshold for spike activation with enhanced firing properties because of the shift of steady-state inactivation and the reduction in current density of $I_{\mathrm{A}}$ channels. The increased excitability of bladder afferent neurons may contribute to the facilitation of bladder reflexes after CYP treatment.

When CYP is injected systemically for the treatment of cancer, the bladder is affected by the toxic actions of acrolein, a metabolite of CYP excreted in the urine (Cox, 1979). It has been documented that a common side effect in patients receiving CYP treatment is hemorrhagic cystitis (Stillwell and Benson, 1988). Animal studies also indicated that CYP treatment in the rat induces cystitis that is characterized by histological changes in the bladder as well as increased frequency of voiding in awake rats and bladder hyperreflexia in anesthetized rats (Maggi et al., 1992, Lecci et al., 1994, Lantéri-Minet et al., 1995; Vizzard et al., 1996). Capsaicin pretreatment reduces the CYP-induced bladder hyperactivity in rats, indicating that it is mediated in part by $\mathrm{C}$-fiber afferents (Maggi et al., 1992). The initial stimulating effects of CYP that occur within a few hours after injection of CYP are very likely mediated by the effects of inflammatory mediators such as $\mathrm{PGE}_{2}, 5 \mathrm{HT}$, histamine, ATP, and nerve growth factor (NGF) on afferent terminals in the bladder wall. In addition, the present results indicate that CYP produces more delayed effects that can alter the properties of ion channels in bladder afferent neurons.

This study was conducted on an identified population of afferent neurons that innervated the inflamed target organ (i.e., bladder) using a combination of retrograde tracing and patch-clamp recording techniques. $\mathrm{C}$-fiber bladder afferent neurons were then identified by the presence of action potentials that were insensitive to TTX. Previous studies demonstrated that TTX-resistant action potentials are attributable to activation of TTX-resistant $\mathrm{Na}^{+}$channels in a subpopulation of afferent neurons (Elliott and Elliott, 1993; Ogata and Tatebayashi, 1993; Arbuckle and Docherty, 1995; Yoshimura et al., 1996; Scholz et al., 1998a). TTXresistant $\mathrm{Na}^{+}$channels have been cloned from rat DRG neurons, and the expression of these channels is confined to the capsaicinsensitive, small-sized DRG neurons (Arbuckle and Docherty, 1995; Akopian et al., 1996; Sangameswaran et al., 1996; Dib-Hajj et al., 1998). Our previous study also indicated that most (over $95 \%$ ) of the capsaicin-sensitive bladder afferent neurons from normal rats were the $\mathrm{C}$-fiber (unmyelinated) afferent type that did not stain with antibodies against a $200 \mathrm{kDa}$ subunit of neurofilament, which is specifically expressed in myelinated DRG neurons (Lawson et al., 1993), whereas only a small proportion (5\%) of A $\delta$-fiber bladder afferent neurons were sensitive to capsaicin (Yoshimura et al., 1998). Thus, it is reasonable to assume that bladder afferent neurons with TTX-resistant long-duration spikes mainly represented $\mathrm{C}$-fiber afferent neurons. The correlation of spike characteristics with other electrical and morphological properties of the neuron such as somal size, action potential thresholds, and duration was also reported by other investigators in unspecified DRG neurons (Waddell and Lawson, 1990; Gold et al., 1996a; Cardenas et al., 1997). Thus it is reasonable to conclude that the CYP-induced changes in bladder afferent neurons occurred in capsaicin-sensitive C-fiber afferent neurons. This conclusion is also consistent with the previous findings in vivo that CYP-induced bladder hyperactivity was abolished by capsaicin pretreatment, which desensitizes C-fiber afferents (Maggi et al., 1992).

The present study also indicates that increased excitability of $\mathrm{C}$-fiber bladder afferent neurons was caused by an alteration of slowly inactivating $I_{\mathrm{A}}$ channels. It has been documented that at least two different types of transient $I_{\mathrm{A}}$ currents are expressed in sensory neurons such as nodose ganglia and DRG cells (McFar- 
lane and Cooper, 1991; Akins and McCleskey, 1993; Gold et al., 1996c). One of these $I_{\mathrm{A}}$ currents exhibits slow inactivation that is quite different from the typical fast inactivation of other $I_{\mathrm{A}}$ currents. This slowly inactivating $I_{\mathrm{A}}$ has an inactivation time constant between 150 and $300 \mathrm{msec}$, and the voltage of halfmaximal inactivation is reportedly displaced to a more positive membrane potential when compared with the fast inactivating $I_{\mathrm{A}}$ currents (McFarlane and Cooper, 1991; Akins and McCleskey, 1993). In addition, Gold et al. (1996c) reported that the slowly inactivating $I_{\mathrm{A}}$ was selectively expressed in DRG neurons that had action potentials with inflections and responded to capsaicin, whereas the fast inactivating $I_{\mathrm{A}}$ was observed in large-diameter DRG neurons without action potential inflections. Our previous study also demonstrated that bladder afferent neurons exhibited a similar distribution of two types of $I_{\mathrm{A}}$ current; i.e., small-sized neurons with TTX-resistant humped spikes expressing slowinactivating $I_{\mathrm{A}}$ and large-sized neurons with TTX-sensitive spikes exhibiting fast inactivating $I_{\mathrm{A}}$ currents (Yoshimura et al., 1996; Yoshimura, 1999). In bladder afferent neurons, the steady-state inactivation of slowly inactivating $I_{\mathrm{A}}$ currents was displaced by $\sim 20 \mathrm{mV}$ in a more depolarizing direction than that of the fast inactivating $I_{\mathrm{A}}$ currents. Thus $\sim 20 \%$ of the slow $I_{\mathrm{A}}$ currents are available at the resting membrane potential level between -50 and $-60 \mathrm{mV}$, whereas fast $I_{\mathrm{A}}$ currents are almost completely inactivated at the resting membrane potential level (Yoshimura et al., 1996). This is in accordance with the findings in our previous and present studies that bladder afferent neurons with TTXresistant spikes exhibited membrane potential relaxation during depolarization that was blocked by an application of 4-AP, a substance that suppresses $I_{\mathrm{A}}$ currents (Fig. 4). 4-AP also reduced the threshold for eliciting an action potential and unmasked tonic firing in C-fiber bladder afferent neurons. Thus, in C-fiber bladder afferent neurons with TTX-resistant spikes, slow $I_{\mathrm{A}}$ currents seem to contribute to the high thresholds for spike activation and suppression of repetitive firing in the normal condition.

The contribution of other $\mathrm{K}^{+}$channels to the regulation of excitability in bladder afferent neurons must be considered because it has been reported that some sustained $\mathrm{K}^{+}$currents in DRG neurons are also subject to steady-state inactivation as occurs in $I_{\mathrm{A}}$ currents (Akins and McCleskey, 1993; Gold et al., 1996c). Thus the slow $I_{\mathrm{A}}$ currents in this study that were isolated by subtracting the current evoked from $-40 \mathrm{mV}$ from that evoked from $-120 \mathrm{mV}$ might possibly contain sustained $\mathrm{K}^{+}$currents subject to steady-state inactivation. However, this seems unlikely because the currents obtained in this manner were totally blocked by 4 -AP $(2 \mathrm{mM})$ in this study, whereas sustained $\mathrm{K}^{+}$currents exhibiting steady-state inactivation were reportedly insensitive to 4-AP up to $5 \mathrm{~mm}$ (Gold et al., 1996c). Thus the expression of sustained $\mathrm{K}^{+}$currents subject to steady-state inactivation is apparently minimal in $\mathrm{C}$-fiber bladder afferent neurons.

The contribution of $\mathrm{K}^{+}$channels to suppression of tonic firing in unspecified DRG neurons has also been identified by other investigators. For example, Waddell and Lawson (1990) revealed that the size of afterhyperpolarization is related to firing pattern (single or multiple spikes) of DRG neurons in response to current injection. More recently, it has been reported that largeconductance $\mathrm{Ca}^{2+}$-activated $\mathrm{K}^{+}$channels $\left(B K_{\mathrm{Ca}}\right)$ that are expressed in a subpopulation of small DRG neurons suppressed repetitive firing in these neurons (Scholz et al., 1998b). Thus it is reasonable to assume that different types of $\mathrm{K}^{+}$channels can modulate the firing pattern in DRG neurons. It has also been suggested that in addition to $\mathrm{K}^{+}$channels, the difference in kinetics of recovery from inactivation between TTX-resistant and TTX-sensitive $\mathrm{Na}^{+}$currents can alter firing pattern in response to sustained membrane depolarization in DRG neurons, although there seems to be a heterogeneity in repriming kinetics of TTX-resistant $\mathrm{Na}^{+}$channels (Elliott and Elliott, 1993; Ogata and Tatebayashi, 1993).

As shown in this study, after CYP-induced cystitis the inactivation curve of the slow $I_{\mathrm{A}}$ current was displaced by $10-15 \mathrm{mV}$ to more hyperpolarized levels, and the peak current density of slow $I_{\mathrm{A}}$ current in $\mathrm{C}$-fiber bladder afferent neurons with TTX-resistant spikes was reduced by $60 \%$. Because of these changes in the slow $I_{\mathrm{A}}$ current after chronic cystitis, action potentials in C-fiber bladder afferent neurons were activated at lower thresholds with increased frequency of firing. Thus it is reasonable to assume that chronic irritation of bladder mucosa alters the inactivation kinetics and current density of slow $I_{\mathrm{A}}$ channels, which are preferentially expressed in capsaicin-sensitive $\mathrm{C}$-fiber bladder afferent neurons, and thereby increases the excitability of these neurons.

Other studies have also shown that tissue inflammation can alter the properties of sensory neurons. Increased expression of various neurotransmitters such as CGRP, substance P, or enkephalin in sensory neurons has been detected in a model of somatic inflammation (Noguci et al., 1989; Donaldson et al., 1992; Smith et al., 1992). Recent studies (Vizzard et al., 1996) in rats with CYP-induced cystitis also demonstrated that chronic bladder irritation upregulated the expression of nitric oxide synthase in bladder afferent neurons. Nitric oxide produced by bladder afferent neurons might be involved in an enhancement of micturition reflex after bladder irritation (Kakizaki and de Groat, 1996).

Although the mechanisms responsible for the delayed onset changes in functional and/or chemical properties of sensory neurons are uncertain, it is possible that neurotrophic factors such as NGF or inflammatory agents such as $\mathrm{PGE}_{2}$, which play a role in acute afferent sensitization, might be involved in the changes noted in the present experiments. For example, NGF is known to be increased in the bladder after inflammation (Steers and Tuttle, 1997; Oddiah et al., 1998), and local administration of NGF can sensitize afferent terminals in the bladder to induce hyperactivity (Dmitrieva and McMahon, 1996). NGF can also contribute to chronic pathology-induced changes in bladder function. Steers and coworkers (1991) discovered that NGF levels increased in the hypertrophied bladders of rats after chronic partial urethral obstruction. Autoimmunization against NGF suppressed the bladder hyperactivity and hypertrophy of bladder afferent neurons occurring in these rats (Steers et al., 1996). The morphological properties of afferent neurons in other systems are also known to be influenced by NGF. For example, chronic administration of NGF increased the size of small-diameter rat DRG neurons (Kornblum and Johnson, 1982), whereas overexpression of NGF in the skin of transgenic mice induces hyperalgesia, an increase in the number of sensory fibers, and somal hypertrophy of afferent neurons in the trigeminal ganglia (Goodness et al., 1997). It has also been documented that NGF can alter capsaicin sensitivity in DRG neurons (Aguayo and White, 1992; Bevan and Winter, 1995). Therefore, it might be expected that chronic bladder irritation would increase capsaicin sensitivity in bladder afferent neurons. However, in this study there were no apparent changes in the number of capsaicin-sensitive bladder afferent neurons or the amplitude of capsaicin-evoked currents after chronic bladder inflammation. Hu-Tsai et al. (1996) also reported no apparent changes in capsaicin sensitivity in DRG neurons from rats with 
inflammation of hindpaw, suggesting that expression of capsaicin sensitivity in DRG neurons is maximal under normal conditions. However, another study in rats revealed that carrageenaninduced subcutaneous inflammation increased axonal transport of the capsaicin receptor (VR1) mRNA in primary afferents and increased the behavioral responses to capsaicin in rats (Tohda et al., 1998). Thus inflammation might change the capsaicin responses at receptors in tissues but not in the DRG cells.

It is also known that $\mathrm{NGF}$ or $\mathrm{PGE}_{2}$ can modulate ion channels in afferent neurons. Chronic administration of NGF can alter the expression of $\mathrm{Na}^{+}$and $\mathrm{K}^{+}$currents in somatic DRG neurons (Aguayo and White, 1992; Black et al., 1997; Oyelese et al., 1997; Everill and Kocsis, 1998), and acute application of $\mathrm{PGE}_{2}$ to DRG neurons modulates the activity of $\mathrm{K}^{+}$and TTX-resistant $\mathrm{Na}^{+}$ channels to induce tonic firing (England et al., 1996; Gold et al., 1996b; Cardenas et al., 1997; Nicol et al., 1997). Thus it is tempting to speculate that, in addition to acute sensitization of afferent terminals, long-term exposure to inflammatory mediators may produce additional effects on the cell body to alter the expression and/or properties of ion channels, as shown in the present study. These mechanisms may account for the emergence of bladder hyperactivity and hyperalgesia after chronic bladder inflammation. We have described previously another example of increased excitability of bladder afferent neurons attributable to neural-target organ interactions. In rats with chronic spinal cord injury, we found not only somal hypertrophy and suppression of slow $I_{\mathrm{A}}$ channels but also increased expression of TTX-sensitive $\mathrm{Na}^{+}$channels, which was not seen after bladder inflammation in this study (Yoshimura and de Groat, 1997; Yoshimura, 1999). Thus, although we propose that phenotypic changes in bladder afferent neurons after spinal cord injury and chronic bladder inflammation are mediated at least in part by trophic signals from the bladder, different mechanisms appear to be involved in neural-target organ interactions under different pathological conditions.

\section{REFERENCES}

Aguayo LG, White G (1992) Effects of nerve growth factor on TTX- and capsaicin-sensitivity in adult rat sensory neurons. Brain Res 570:61-67.

Akins PT, McCleskey EW (1993) Characterization of potassium currents in adult rat sensory neurons and modulation by opioids and cyclic AMP. Neuroscience 56:759-769.

Akopian AN, Sivilotti L, Wood JN (1996) A tetrodotoxin-resistant voltage-gated sodium channel expressed by sensory neurons. Nature 379:257-262.

Arbuckle JB, Docherty RJ (1995) Expression of tetrodotoxin-resistant sodium channels in capsaicin-sensitive dorsal root ganglion neurons of adult rats. Neurosci Lett 185:70-73.

Belluzzi O, Sacchi O, Wanke E (1985) A fast transient outward current in the rat sympathetic neurone studied under voltage-clamp conditions. J Physiol (Lond) 358:91-108.

Bevan S, Winter J (1995) Nerve growth factor (NGF) differentially regulates the chemosensitivity of adult rat cultured sensory neurons. J Neurosci 15:4918-4926.

Black JA, Langworthy K, Hinson AW, Dib-Haji SD, Waxman SG (1997) NGF has opposing effects on $\mathrm{Na}^{+}$channel III and SNS gene expression in spinal sensory neurons. NeuroReport 8:2331-2335.

Cardenas CG, Del Mar LP, Cooper BY, Scroggs RS (1997) $5 \mathrm{HT}_{4}$ receptors couple positively to tetrodotoxin-insensitive sodium channels in a subpopulation of capsaicin-sensitive rat sensory neurons. J Neurosci 17:7181-7189.

Cox PJ (1979) Cyclophosphamide cystitis: identification of acrolein as the causative agent. Biochem Pharmacol 28:2045-2049.

Dib-Hajj SD, Tyrrell L, Black JA, Waxman SG (1998) NaN, a novel voltage gated $\mathrm{Na}$ channel, is expressed preferentially in peripheral sensory neurons and down-regulated after axotomy. Proc Natl Acad Sci USA 95:8963-8968.
Dmitrieva N, McMahon SB (1996) Sensitisation of visceral afferents by nerve growth factor in the adult rat. Pain 66:87-97.

Dmitrieva N, Shelton D, Rice ASC, McMahon SB (1997) The role of nerve growth factor in a model of visceral inflammation. Neuroscience 78:449-459.

Donaldson LF, Harmar AJ, McQueen DS, Seckl JR (1992) Increased expression of preprotachykinin, calcitonin gene-related peptide, but not vasoactive intestinal peptide messenger RNA in dorsal root ganglia during the development of adjuvant monoarthritis in the rat. Mol Brain Res 16:143-149.

Elliott AA, Elliott JR (1993) Characterization of TTX-sensitive and TTX-resistant sodium currents in small cells from adult rat dorsal root ganglia. J Physiol (Lond) 463:39-56.

England S, Bevan S, Docherty RJ (1996) $\mathrm{PGE}_{2}$ modulates the tetrodotoxin-resistant sodium current in neonatal rat dorsal root ganglion neurones via the cyclic AMP-protein kinase A cascade. J Physiol (Lond) 495:429-440.

Everill B, Kocsis JD (1998) Effects of nerve growth factor on potassium conductance after nerve injury in adult cutaneous afferent dorsal root ganglion neurons. Soc Neurosci Abstr 24:1332.

Gold MS, Dastmalchi S, Levine JD (1996a) Co-expression of nociceptor properties in dorsal root ganglion neurons from the adult rat in vitro. Neuroscience 71:265-275.

Gold MS, Reichling DB, Shuster MJ, Levine JD (1996b) Hyperalgesic agents increase a tetrodotoxin-resistant $\mathrm{Na}^{+}$current in nociceptors. Proc Natl Acad Sci USA 93:1108-1112.

Gold MS, Shuster MJ, Levine JD (1996c) Characterization of six voltage gated $\mathrm{K}^{+}$currents in adult rat sensory neurons. J Neurophysiol 75:2629-2646.

Goodness TP, Albers KM, Davis FE, Davis BM (1997) Overexpression of nerve growth factor in skin increases sensory neuron size and modulates Trk receptor expression. Eur J Neurosci 9:1574-1585.

Häbler HJ, Jänig W, Koltzenburg M (1990) Activation of unmyelinated afferent fibres by mechanical stimuli and inflammation of the urinary bladder in the cat. J Physiol (Lond) 425:545-562.

Ho N, Koziol JA, Parsons CL (1997) Epidemiology of interstitial cystitis. In: Interstitial cystitis (Sant GR, ed), pp 9-16. Philadelphia: Lippincott-Raven.

Hu-Tsai M, Woolf C, Winter J (1996) Influence of inflammatory or disconnection from peripheral target tissue on the capsaicin sensitivity of rat dorsal root ganglion sensory neurones. Neurosci Lett 203:119-122.

Johansson SL, Ogawa K, Fall M (1997) The pathology of interstitial cystitis. In: Interstitial cystitis (Sant GR, ed), pp 143-152. Philadelphia: Lippincott-Raven.

Kakizaki H, de Groat WC (1996) Role of spinal nitric oxide in the facilitation of the micturition reflex by bladder irritation. J Urol 155:355-360.

Kornblum HI, Johnson EM (1982) Time and dose dependencies of effects of nerve growth factor on sympathetic and sensory neurons in neonatal rats. Brain Res 234:41-51.

Lantéri-Minet M, Bon K, de Pommery J, Michiels JF, Menétrey D (1995) Cyclophosphamide cystitis as a model of visceral pain in rats: model elaboration and spinal structures involved as revealed by the expression of c-Fos and Krox-24 proteins. Exp Brain Res 105:220-232.

Lawson SN, Perry MJ, Prabhaker E, McCarthy PW (1993) Primary afferent neurones: neurofilament, neuropeptides, and conduction velocity. Brain Res Bull 30:239-243.

Lecci A, Giuliani S, Santiciolo P, Maggi CA (1994) Involvement of spinal tachykinin NK1 and NK2 receptors in detrusor hyperreflexia during chemical cystitis in anesthetized rats. Eur J Pharmacol 259:129-135.

Li Z, Chapleau MW, Bates JN, Bielefeldt K, Lee H-C, Abboud FM (1998) Nitric oxide as an autocrine regulator of sodium currents in baroreceptor neurons. Neuron 20:1039-1049.

Maggi CA, Lecci A, Santicioli P, Bianco ED, Giuliani S (1992) Cyclophosphamide cystitis in rats: involvement of capsaicin-sensitive primary afferents. J Auton Nerv Syst 38:201-208.

McFarlane S, Cooper E (1991) Kinetics and voltage dependence of A-type currents on neonatal rat sensory neurons. J Neurophysiol 66:1380-1391.

McMahon SB (1996) NGF as a mediator of inflammatory pain. Philos Trans R Soc Lond B Biol Sci 351:431-440.

Millan MJ (1999) The induction of pain: an integrative review. Prog Neurobiol 57:1-164. 
Nicol GD, Vasko MR, Evans AR (1997) Prostaglandins suppress an outward potassium current in embryonic rat sensory neurons. J Neurophysiol 77:167-176.

Noguchi K, Morita Y, Kiyama H, Sato M, Ono K, Tohyama M (1989) Proenkephalin gene expression in the rat spinal cord after noxious stimulation. Mol Brain Res 5:227-234.

Oddiah D, Anand P, McMahon SB, Rattray M (1998) Rapid increase of NGF, BDNF and NT-3 mRNAs in inflamed bladder. NeuroReport 9:1455-1458.

Ogata N, Tatebayashi $\mathrm{H}$ (1993) Kinetic analysis of two types of $\mathrm{Na}^{+}$ channels in rat dorsal root ganglia. J Physiol (Lond) 466:9-37.

Oyelese AA, Rizzo MA, Waxman SG, Kocsis JD (1997) Differential effects of NGF and BDNF on axotomy-induced changes in $\mathrm{GABA}_{\mathrm{A}^{-}}$ receptor-mediated conductance and sodium currents in cutaneous afferent neurons. J Neurophysiol 78:31-42.

Rudy B (1988) Diversity and ubiquity of K channels. Neuroscience 25:729-749.

Sangameswaran L, Delgado SG, Fish LM, Koch BD, Jakeman LB, Stewart GR, Sze P, Hunter JC, Eglen RM, Herman RC (1996) Structure and function of a novel voltage-gated, tetrodotoxin-resistant sodium channel specific to sensory neurons. J Biol Chem 271:5953-5956.

Scholz A, Kuboyama N, Hempelmann G, Vogel W (1998a) Complex blockade of TTX-resistant $\mathrm{Na}^{+}$currents by lidocaine and bupivacaine reduce frequency in DRG neurons. J Neurophysiol 79:1746-1754.

Scholz A, Gru $\beta$ M, Vogel W (1998b) Properties and functions of calcium-activated $\mathrm{K}^{+}$channels in small neurones of rat dorsal root ganglion studied in a thin slice preparation. J Physiol (Lond) 513:55-69.

Sengupta JN, Gebhart GF (1994) Mechanosensitive properties of pelvic nerve afferent fibres innervating the urinary bladder of the rat. J Neurophysiol 72:2420-2430.

Smith GD, Harmar AJ, McQueen DS, Seckl JR (1992) Increase in substance $\mathrm{P}$ and CGRP, but not somatostatin content of innervating dorsal root ganglia in adjuvant monoarthritis in the rat. Neurosci Lett 137:257-260.

Steers WD, Tuttle JB (1997) Neurogenic inflammation and nerve growth factor: possible roles in interstitial cystitis. In: Interstitial cystitis (Sant GR, ed), pp 67-76. Philadelphia: Lippincott-Raven.

Steers WD, Kolbeck S, Creedon D, Tuttle JB (1991) Nerve growth factor in the urinary bladder of the adult regulates neuronal form and function. J Clin Invest 88:1709-1715.

Steers WD, Creedon DJ, Tuttle JB (1996) Immunity to nerve growth factor prevents afferent plasticity following urinary bladder hypertrophy. J Urol 155:379-385.

Stillwell TJ, Benson RC (1988) : Cyclophosphamide-induced cystitis. A review of 100 patients. Cancer 61:451-457.

Tohda C, Sasaki M, Kuraishi Y (1998) Axonal transport of capsaicin receptor messenger RNA in primary afferents of rats with hyperalgesia induced by carrageenan. Soc Neurosci Abstr 24:384.

Vizzard MA, Erdman SL, de Groat WC (1996) Increased expression of neuronal nitric oxide synthesis in bladder afferent pathway following chronic bladder irritation. J Comp Neurol 370:191-202.

Waddell PJ, Lawson SN (1990) Electrophysiological properties of subpopulations of rat dorsal root ganglion neurons in vitro. Neuroscience $36: 811-822$.

Yoshimura N (1999) Bladder afferent pathway and spinal cord injury: possible mechanisms inducing hyperreflexia of the urinary bladder. Prog Neurobiol 57:583-606.

Yoshimura N, de Groat WC (1997) Plasticity of $\mathrm{Na}^{+}$channels in afferent neurones innervating rat urinary bladder following spinal cord injury. J Physiol (Lond) 503:269-276.

Yoshimura N, de Groat WC (1998) Hyperexcitability and somal hypertrophy of bladder afferent neurons following chronic bladder inflammation in the rat. J Urol 159:306A.

Yoshimura N, White G, Weight FF, de Groat WC (1994) Patch-clamp recordings from subpopulations of autonomic and afferent neurons identified by axonal tracing techniques. J Auton Nerv Syst 49:86-92.

Yoshimura N, White G, Weight FF, de Groat WC (1996) Different types of $\mathrm{Na}^{+}$and $\mathrm{K}^{+}$currents in rat dorsal root ganglion neurones innervating the urinary bladder. J Physiol (Lond) 494:1-16.

Yoshimura N, Parrish ME, de Groat WC (1997) Increased excitability of bladder afferent neurons following chronic bladder inflammation in the rat. International Research Symposium on Interstitial Cystitis, Abstract, p 102.

Yoshimura N, Erdman SL, Snider MW, de Groat WC (1998) Effects of spinal cord injury on neurofilament immunoreactivity and capsaicin sensitivity in rat dorsal root ganglion neurons innervating the urinary bladder. Neuroscience 83:633-643. 